\title{
Análise das políticas institucionais de catalogação em bibliotecas de ensino superior de Florianópolis (Santa Catarina, Brasil)
}

Priscilla Lüdtke Espíndola

Ana Maria Pereira

Universidade do Estado de Santa Catarina - UDESC, Brasil

CASE REPORT

\begin{abstract}
Resumo
Objetivo. A presente pesquisa possui como objetivo geral verificar se as Bibliotecas de Ensino Superior (BES), situadas no município de Florianópolis (Santa Catarina, Brasil), possuem políticas institucionais formalizadas para guiar seus processos de catalogação.

Método. A metodologia empregada foi de caráter exploratório, do tipo documental, com abordagem qualiquantitativa. Para coleta de dados, foram realizados o levantamento em sites institucionais e a investigação nas BES, por meio de telefone e/ou e-mail. A análise dos dados foi concretizada por meio da análise documental, com roteiro previamente definido.

Resultados. Como resultado, constatou-se que nenhuma das BES estudadas apresenta Políticas Institucionais de Catalogação, uma vez que os documentos disponibilizados não possuem os requisitos mínimos necessários para serem caracterizados como tal; no entanto, apresentam alguns itens que devem constar nas Políticas Institucionais de Catalogação, tais como: indicativo de data de elaboração; diretrizes para controle de autoridades; e indicação de regras e/ou de instrumentos auxiliares adotados.
\end{abstract}

\section{Palavras-chave}

Bibliotecas de Ensino Superior; Brasil; Diretrizes administrativas para catalogação; Política de catalogação; Políticas aplicadas a bibliotecas; Santa Catarina

\section{Cataloging Policies Analysis in Libraries of Higher Education Located in Florianópolis (Santa Catarina, Brazil)}

\begin{abstract}
Objective. The present paper aims to verify if the Libraries of Higher Education located in Florianópolis (Santa Catarina, Brazil) have formalized cataloging policies to guide your cataloging processes.

Method. The methodology applied was an exploratory research, of a documental kind, with qualitative and quantitative approach. To collect data, surveys in institutional websites and investigations at the Libraries of Higher Education (by phone and/or e-mail) were carried out. The data analysis was achieved by means of a documentary analysis, with a previously defined guide.

Results. As result was found that, because the documents do not have the minimal requirements to been characterized in this way, no one of the Libraries of Higher Education have Cataloging Policies. Nevertheless, they have some items that must appear in Cataloging Policies, like elaboration date, guidelines for authority control and indication of rules and / or auxiliary instruments adopted.
\end{abstract}

Keywords

Brazil; Cataloging Policy; Guidelines for Cataloging; Libraries of Higher Education; Policies for libraries; Santa Catarina 


\section{Introdução}

Para que um registro do conhecimento consiga ser localizado pelo usuário, de maneira que este utilize o conteúdo registrado para atender às suas necessidades de trabalho, estudo e lazer, faz-se necessária a execução de um conjunto de processos biblioteconômicos. Dentre tais processos, destacam-se os referentes ao tratamento documentário, em que estão contidas a catalogação e a indexação (FUJITA; RUBI; BOCCATO, 2009).

A catalogação, área de estudo da presente pesquisa, é definida por Santos e Pereira (2014) como o processo relacionado à organização sistemática de informações, de dados e de recursos informacionais. Por meio dela, são construídos registros catalográficos sobre os recursos informacionais e referências cruzadas para outros registros e arquivos; além disso, são proporcionadas identificação e descrição (física e de conteúdo) dos recursos catalogados.

Segundo Mey e Silveira (2009), a representação de um registro do conhecimento deve ser realizada uma única vez, de modo que não haja desperdícios de tempo da equipe e duplicidade de trabalho. Portanto, compreendese que a eficiência na catalogação é indispensável para o aproveitamento do tempo dos catalogadores, pois, ao executar as atividades de catalogação de acordo com os objetivos da Unidade de Informação (UI) e sem desperdício de recursos, o catalogador fica disponível para desenvolver outras tarefas que podem gerar mais produtos e serviços para a Instituição.

Os manuais de procedimentos e as políticas institucionais são exemplos de documentos que podem ser empregados na catalogação para torná-la mais eficiente e com maior qualidade. O manual de catalogação auxilia na execução de tarefas técnicas do processo de catalogação e no treinamento dos colaboradores de uma UI. Vosgrau et al. (2010) consideram referido manual como uma ferramenta de gestão da qualidade da informação que objetiva o aprimoramento da catalogação e o envolvimento de todos os colaboradores no processo decisório.

A Política Institucional de Catalogação, nosso objeto de estudo, é composta por um conjunto de diretrizes que visam orientar o catalogador em qual decisão tomar em casos cotidianos relacionados às atividades de catalogação em uma UI, ou em uma Rede de Cooperação de Uls.

Silva (2009) apresenta diversas finalidades de uma Política Institucional de Catalogação, tais como: proporcionar melhorias na qualidade dos produtos finais da catalogação; assegurar que as decisões referentes ao processo de catalogação sejam uniformes, quer ao longo dos anos de funcionamento da UI, quer pelos diferentes catalogadores responsáveis pela catalogação na instituição; aumentar a eficácia e a eficiência no processo de catalogação; documentar as mudanças ocorridas no processo de catalogação como forma de facilitar futuros processos de conversão e migração de dados, e proporcionar redução dos custos relacionados ao processo de catalogação.

As referidas políticas têm o fim de fornecer um norte para o processo de catalogação, alinhando as decisões relacionadas ao tratamento descritivo dos registros às características da UI e de sua comunidade usuária. Além disso, suas diretrizes administrativas auxiliam os catalogadores na identificação dos limites que devem ser respeitados e da direção a ser seguida na execução das atividades decorrentes do processo de catalogação, de maneira que os objetivos institucionais não sejam negligenciados.

Diante do exposto, tendo em vista os benefícios que a criação e a adoção de Políticas Institucionais de Catalogação podem proporcionar para as Uls, dentre elas as Bibliotecas de Ensino Superior (BES), apresentase a seguinte questão-problema: As BES, situadas no município de Florianópolis, possuem políticas institucionais formalizadas para guiar seus processos de catalogação?

Para responder à referida questão, elaborou-se o seguinte objetivo geral: verificar se as BES, situadas no município de Florianópolis, possuem políticas institucionais formalizadas para guiar seus processos de catalogação. Como objetivos específicos a investigação busca identificar os documentos institucionais utilizados pelas BES, localizadas em Florianópolis, para guiar seus processos de catalogação; coletar referidos documentos para análise; elaborar um roteiro para analisar os documentos fornecidos pelas BES; averiguar, 
com base na análise realizada, quais das BES estudadas possuem Políticas Institucionais de Catalogação formalizadas e traçar um panorama da utilização de Políticas Institucionais de Catalogação nas BES estudadas.

Para tanto, optou-se por delimitar o universo desta pesquisa para BES de Instituições de Ensino Superior (IES) públicas e privadas, do município de Florianópolis (Estado de Santa Catarina, Brasil), credenciadas pelo Ministério da Educação (MEC), com Índice Geral de Cursos (IGC) igual ou superior a 3, em 2013. O IGC é um dos indicadores de qualidade empregados pelo Instituto Nacional de Estudos e Pesquisas Educacionais Anísio Teixeira (Inep) para avaliação das IES do território brasileiro (BRASIL, 2015a).

No entanto, ressalta-se que se adotou a denominação BES para representar as Uls estudadas, pois elas são mantidas administrativa e economicamente por IES públicas e privadas de diversas naturezas acadêmicas (universidades, centros universitários, faculdades e institutos federais), portanto, não restritas às Universidades e, consequentemente, às Bibliotecas Universitárias.

Na literatura científica da área da Biblioteconomia, identificou-se um número reduzido de trabalhos sobre a temática Políticas Institucionais de Catalogação. A escassez de publicações relacionadas ao tema políticas aplicadas à catalogação foi constatada por Sousa (2015), que apresenta um levantamento de trabalhos, referentes a tais políticas, em bases de dados da Ciência da Informação internacionais e nacionais. Nesse levantamento, a autora recuperou somente dois artigos que abordam a temática Política Institucional de Catalogação, evidenciando a necessidade de mais pesquisas científicas sobre o tema.

Diante desse contexto, este trabalho visa contribuir com o desenvolvimento da área de catalogação ao analisar a criação e a adoção de Políticas Institucionais de Catalogação em BES, localizadas no município de Florianópolis.

Por meio deste estudo, foi traçado um panorama da utilização de políticas institucionais no processo de catalogação nas BES estudadas para compreender como suas diretrizes podem auxiliar os catalogadores dessas instituições a alcançar mais eficiência nas atividades desenvolvidas e a gerar registros bibliográficos de melhor qualidade.

\section{Políticas institucionais de catalogação}

As Uls, como as bibliotecas e os centros de documentação, são organizações, na maior parte das vezes, sem fins lucrativos e que objetivam atender às necessidades informacionais dos seus usuários, a fim de alcançar a satisfação deles.

No entendimento de Maciel e Mendonça (2006), pensar nas bibliotecas como organizações facilita o gerenciamento dessas, visto que, assim, os bibliotecários conseguem perceber que, como qualquer outra organização, as bibliotecas necessitam proporcionar produtos e serviços de qualidade, bem como planejar e avaliar seus resultados constantemente. Conforme as autoras, ao adotar essa estratégia, as bibliotecas podem mais facilmente desenvolver um perfil competitivo e inovador para manterem-se no mercado econômico atual.

Rocha e Gomes (1993) lembram que, na literatura científica, são encontrados diversos conceitos de qualidade, não existindo uma definição padrão. No entanto, segundo as autoras, todos os termos localizados refletem que a qualidade está associada à satisfação da clientela e à conquista e garantia do mercado.

A qualidade nos serviços e produtos desenvolvidos pelas Uls é essencial para a satisfação dos usuários, de forma que, ao se sentirem satisfeitos, os usuários tendem a ser motivados a retornarem à Instituição para utilizarem seus recursos, assim como tendem a indicar esses recursos para seus familiares e amigos.

Spudeit e Führ (2011) colaboram com a visão de Maciel e Mendonça (2006) ao afirmarem que as Uls devem planejar estrategicamente, buscando investir em diferenciais na prestação de seus serviços, para satisfazer as expectativas de seus usuários e, consequentemente, garantir sua permanência no mercado. 
Segundo Almeida (2005), o planejamento deve estar incorporado à rotina da UI, pois auxilia os colaboradores na execução das atividades técnicas e administrativas, definindo os objetivos pretendidos e o caminho a ser traçado para atingi-los, com o mínimo de gastos desnecessários de recursos e de tempo possível.

Por meio do planejamento, é possível antever os problemas que podem ser encontrados durante a execução de atividades, analisando antecipadamente as soluções disponíveis e definindo a melhor ação a ser tomada, a fim de garantir que os objetivos da UI e de sua Instituição mantenedora sejam alcançados (ALMEIDA, 2005). Desse modo, a UI minimiza surpresas, agrega maior segurança aos seus processos e evita o desperdício de recursos.

Entende-se como fundamental que as Uls realizem o seu planejamento como forma de agregar mais qualidade aos serviços e aos produtos que entregam aos usuários. Uma vez que, ao antever ocorrências que possam prejudicar os serviços e produtos oferecidos aos usuários, a UI aplica medidas preventivas, evitando que sejam necessárias ações paliativas, imediatistas e sem embasamento.

O planejamento pode ser empregado a diversos processos de uma UI, dentre eles a catalogação. Compreendese que, ao planejar e ao avaliar o processo de catalogação, o catalogador possui maior embasamento para tomar decisões, para propor melhorias às atividades desempenhadas e para traçar ações que agreguem cada vez mais qualidade aos registros catalográficos gerados, e, por conseguinte, ao catálogo bibliográfico.

Mey e Silveira (2009) definem a catalogação como o processo técnico de descrição bibliográfica, definição de pontos de acesso e de dados de localização dos registros do conhecimento de uma UI (ou de uma rede), cujo objetivo é dar subsídios aos usuários para localizarem de modo físico, ou obterem acesso de modo digital, os recursos de que necessitam. A catalogação é um dos processos biblioteconômicos cuja finalidade é proporcionar maior eficácia na recuperação das informações armazenadas em sistemas de informação.

No entanto, para garantir maior exatidão na recuperação dos registros por meio do catálogo bibliográfico, é indispensável que a catalogação empregue padrões e regras que ofereçam o máximo de padronização e o mínimo de interpretações individuais. Tais regras e padrões visam proporcionar maior uniformidade à descrição dos registros do conhecimento, em qualquer idioma e em qualquer tipo de UI (SANTOS; CORRÊA, 2009).

Dentro desse contexto, entende-se como essencial a adoção de padrões e regras internacionais de catalogação nas Uls, assim como a criação de documentos administrativos que alinhem esses padrões e regras aos objetivos de cada Instituição e às necessidades específicas de suas comunidades usuárias. Dentre tais documentos, destacam-se as Políticas Institucionais de Catalogação e os Manuais de Catalogação.

De acordo com Sousa (2015), o próprio Código de Catalogação Anglo-Americano segunda edição, denominado AACR2, orienta que algumas de suas regras devem ser analisadas e avaliadas conforme o contexto de cada UI, e que, após a definição das alternativas que serão adotadas institucionalmente, estas devem ser incorporadas à sua Política de Catalogação.

Entretanto, antes de abordar as características e finalidades de referidos documentos específicos, convém primeiramente apresentar, de maneira genérica, as políticas institucionais e os manuais de procedimentos, como documentos que têm a finalidade de auxiliar o alcance da eficácia do planejamento de ações nas Uls (ALMEIDA, 2005).

Koontz, O'Donnell e Weihrich (1987) lembram que as políticas consistem em um conjunto de noções gerais que orientam o raciocínio e a tomada de decisões, mas que devem permitir necessariamente certa medida de ação discricionária. Ou seja, as políticas apresentam orientações que guiam para a tomada de decisão e estimulam o uso de discrição e iniciativa, dentro dos limites estipulados pela organização. Assim, a política deve orientar os colaboradores a tomar decisões, mas não limitar suas ações, caso contrário, seria rígida como regras que não deixam margem para ações criativas e inovadoras.

Ainda no entendimento dos autores, as políticas devem assegurar que as decisões tomadas pelos colaboradores sejam compatíveis com os objetivos institucionais e delimitar uma área dentro da qual tais decisões podem ser tomadas, mantendo o controle das ações exercidas na instituição. 
Bio (1985), por sua vez, explica que as políticas são guias de raciocínio planejadas para a tomada de decisões repetitivas. Isso significa que, dentro de uma organização, a política é planejada pelos gestores para que os demais colaboradores apliquem, às atividades cotidianas, as mesmas decisões, garantindo alinhamento das ações executadas.

As diretrizes presentes em uma política podem embasar a criação de instrumentos administrativos, como os manuais de procedimentos. Referidos manuais servem para auxiliar na fixação de critérios e de padrões, na orientação e no treinamento de colaboradores da organização, na uniformidade de terminologias técnicas e na padronização das atividades administrativas (OLIVEIRA, 2009).

Almeida (2005) explica que os manuais são guias de execução das decisões e das ações tomadas com auxílio das políticas institucionais. Ainda segundo a autora, tais instrumentos estão relacionados ao registro de métodos rotineiros empregados na execução de determinadas atividades, detalhando a maneira e a sequência exata que as tarefas devem ser realizadas para atingir os objetivos institucionais.

Desse modo, compreende-se que as políticas e os manuais são documentos administrativos que se complementam, pois, enquanto a política orienta a tomada de decisões e de ações, o manual guia na execução das decisões e ações.

As Uls podem adotar políticas em diversos de seus processos, exemplo disso são os tipos de "políticas bibliotecárias" apontadas por Cunha e Cavalcanti (2008). De acordo com os autores (p. 285), a política bibliotecária é a "[...] formulação, formal ou informal, ligada ao atendimento da missão da biblioteca [...]", a qual pode ser de diferentes tipos: política de seleção; política de aquisição; política de descarte; política de desenvolvimento de coleções; política de empréstimo; política de indexação, dentre outras.

O documento formalizado institucionalmente, que apresenta as diretrizes para orientar os catalogadores, é denominado neste estudo como Política Institucional de Catalogação. No entanto, observam-se na literatura outras designações, como Políticas de Representação Descritiva (SOUSA, 2015) e Política de Tratamento da Informação Documentária (FUJITA; RUBI; BOCCATO, 2009), devendo, a última, na visão das autoras, englobar diretrizes para guiar os processos de análises descritiva e temática dos registros do conhecimento.

Silva (2009) define as Políticas Institucionais de Catalogação como um conjunto formalizado de orientações e princípios genéricos que estabelecem diretrizes e limites para as ações dos catalogadores, e que também auxiliam tais profissionais na tomada de decisões referentes ao processo de catalogação.

Ainda em conformidade com o autor, as citadas políticas propõem-se a atender a objetivos, como melhorar a qualidade dos serviços oferecidos pelas Instituições; aumentar a eficácia, a eficiência e a economia do processo de catalogação; aumentar a qualidade dos produtos finais da catalogação (registros e catálogos), garantindo que estejam em consonância com o contexto normativo internacional da catalogação; assegurar a tomada de decisões uniformes, ao longo dos anos de funcionamento da UI, e por diferentes catalogadores responsáveis pelas atividades de catalogação na instituição; documentar as mudanças ocorridas no processo de catalogação no que concerne às normas e às práticas adotadas, com o intuito de facilitar os processos de conversão e migração de dados, e reduzir os custos relacionados ao processo de catalogação.

Read (2003), por sua vez, acrescenta que a Política Institucional de Catalogação serve igualmente a duas funções: formalizar o trabalho realizado no setor de catalogação, garantindo que todos os catalogadores utilizem a mesma metodologia de descrição bibliográfica e de determinação de pontos de acesso, e comunicar internamente, aos demais bibliotecários que não exercem as atividades de catalogação, a metodologia de trabalho empregada nesse processo e o motivo de ser realizada da forma como é realizada.

A Política Institucional de Catalogação está associada à busca pela eficiência e pela eficácia do processo de Catalogação (SILVA, 2009). Ao tornar o processo de catalogação mais eficiente, a Política Institucional de Catalogação orienta os catalogadores a utilizarem o mínimo de recursos (humanos, tecnológicos, financeiros, entre outros) durante a execução das atividades de catalogação, de modo que tais atividades não despendam gastos excessivos. 
Semelhantemente, ao visar que a catalogação seja mais eficaz, a Política Institucional de Catalogação deve garantir que as decisões empregadas durante o processo de catalogação da Ul estejam de acordo com os propósitos de sua Instituição mantenedora, de modo a contribuir para que os resultados planejados por essa sejam atingidos.

Assim, a Política Institucional de Catalogação pode auxiliar os catalogadores a ter maior eficiência e eficácia na execução das atividades relacionadas ao processo de catalogação.

Da mesma maneira, entende-se que a mencionada política é um importante recurso para proporcionar melhorias na qualidade percebida pelos usuários dos produtos da catalogação. Branco et al. (2014) esclarecem que as políticas, dentre outros elementos, são fundamentais para auxiliar o controle de qualidade da catalogação.

A qualidade na catalogação está relacionada, consoante os autores, à criação de registros que representem, com o máximo de precisão e confiabilidade, as informações contidas nos registros do conhecimento. Nesse sentido, erros de grafia, emprego de pontos de acessos equivocados e registros incompletos ou duplicados prejudicam a qualidade da catalogação e, consequentemente, do catálogo bibliográfico, pois dificultam a recuperação da informação por parte dos usuários, criando obstáculos para que tenham acesso ao registro do conhecimento desejado. Os referidos erros de catalogação acabam por gerar, muitas vezes, retrabalhos, já que, ao identificar tais erros, o catalogador tem de retornar ao registro catalográfico armazenado no catálogo e realizar as correções necessárias, ocasionando perda de tempo e de recursos institucionais.

Por meio de uma Política Institucional de Catalogação formalizada, é possível traçar diretrizes que orientem os catalogadores a evitar os erros de catalogação, resultando em registros catalográficos de qualidade e que podem ser recuperados com maior exatidão pelas ferramentas de busca do catálogo bibliográfico.

Dentro desse contexto, salienta-se a necessidade da sistematização das diretrizes da Política Institucional de Catalogação em um documento formal, de modo a evitar que tais diretrizes sejam negligenciadas e seus benefícios inalcançados. Read (2003) explica que as diretrizes institucionais de catalogação são facilmente descuidadas pelos catalogadores quando da existência de grande número de registros do conhecimento para catalogar e da pressa de disponibilizá-los aos usuários.

A autora enfatiza, ainda, que a Política Institucional de Catalogação não pode ser vista como eterna e imutável, pois deve ser revista periodicamente e alterada conforme a necessidade da UI. Sendo assim, entende-se como indispensável a atualização e a revisão periódicas de tais políticas, de forma que suas diretrizes reflitam as mudanças que ocorrem na UI e no perfil de sua comunidade usuária.

$\mathrm{Na}$ visão de Silva (2009), as diretrizes presentes nas Políticas Institucionais de Catalogação devem ser complementadas por manuais de procedimentos de catalogação, os quais contêm orientações que auxiliam os bibliotecários na realização das atividades técnicas de catalogação.

Os Manuais de Catalogação possuem a metodologia institucional a ser aplicada na execução das atividades de catalogação na UI, podendo ser empregados no treinamento de novos catalogadores e como instrumento de consulta diária para resoluções de dúvidas pontuais relacionadas às tarefas técnicas de descrição bibliográfica, definição de pontos de acesso e de dados de localização. Referidos manuais orientam a execução padronizada das tarefas de catalogação, as quais são resultantes das decisões tomadas pelos catalogadores por meio das Políticas Institucionais de Catalogação.

No entanto, Popper (1981) explica que são os manuais que devem espelhar as políticas e não o contrário, uma vez que os manuais devem acompanhar as alterações e as atualizações das políticas institucionais. Dessa forma, ao elaborar e documentar sua Política Institucional de Catalogação, a UI terá subsídios para desenvolver também o seu Manual de Catalogação.

Ao desenvolver e aplicar referidos documentos, a UI terá maior controle de seu processo de catalogação, de modo a garantir que erros sejam minimizados, bem com diminuídos o retrabalho e o desperdício de recursos institucionais. Sendo assim, entende-se que o emprego de Políticas Institucionais de Catalogação em conjunto com Manuais de Catalogação visa garantir mais consistência ao catálogo bibliográfico e agregar mais qualidade aos serviços e aos produtos gerados pela catalogação. 


\section{Procedimentos metodológicos}

Esta pesquisa possui caráter exploratório, do tipo documental e abordagem qualiquantitativa. A coleta de dados foi realizada em julho e agosto de 2015, dividida em duas etapas: (a) busca em sites institucionais das BES; (b) contato com os gestores dessas BES, por telefone e/ou e-mail, solicitando os documentos administrativos utilizados no processo de catalogação. Para análise e interpretação dos dados, empregaram-se a estatística descritiva e a análise documental, com o desenvolvimento de um roteiro de análise.

Quanto aos objetivos, esta pesquisa pode ser classificada como exploratória, pois apresenta como finalidade principal proporcionar maior familiaridade com o problema de estudo: emprego de Políticas Institucionais de Catalogação nas BES situadas em Florianópolis.

De acordo com Alves (2007) em uma pesquisa exploratória seu autor tem como objetivos tornar o problema de estudo mais explícito e aprofundar as ideias relacionadas ao objeto à ser investigado.

A pesquisa documental, conforme Marconi e Lakatos (2013), é a fonte de coleta de dados restrita a fontes primárias, as quais são compiladas por seus próprios autores, como, por exemplo, documentos de arquivos públicos, publicações parlamentares e administrativas, e documentos privados. As fontes primárias utilizadas nesta investigação foram os documentos institucionais empregados para o auxílio do processo de catalogação nas BES estudadas.

Quanto à abordagem, a presente pesquisa é de cunho qualiquantitativo, por analisar e interpretar os dados coletados por intermédio de técnicas quantitativas, como a estatística descritiva, e por meio de técnicas qualitativas, como a análise documental.

De acordo com Flick (2009), a análise documental deve ir além da simples análise de textos, visto que estes servem como meios de comunicação entre o pesquisador e a pessoa ou instituição que os elaboraram. Dessa forma, na visão do autor, por meio da análise dos documentos, é possível igualmente conhecer diversos fatores ligados ao seu contexto de criação.

$\mathrm{Na}$ análise dos documentos disponibilizados pelas BES, objetivou-se compreender aspectos, como o contexto de elaboração e a gestão desses documentos, e as características do processo de catalogação empregado nas BES estudadas.

Ainda, na visão de Flick (2009), a análise documental deve incluir o modo como o documento é constituído, ou seja, o seu layout. Com esse objetivo em mente, analisaram-se, comparativamente, os documentos institucionais fornecidos pelo universo de pesquisa para identificar se apresentam um padrão de estrutura.

Para determinar o universo de estudo, foi necessário, primeiramente, realizar o levantamento das IES públicas e privadas, com ensino presencial, localizadas no município de Florianópolis, credenciadas pelo MEC, por meio do Sistema e-MEC (BRASIL, 2015b). Nesse levantamento, foram identificadas 21 IES com os parâmetros citados.

Em seguida, verificou-se, no Portal do INEP (BRASIL, 2015a), o IGC em 2013 das 21 IES localizadas na primeira etapa. Desse total, treze IES apresentaram IGC superior ou igual a 3, em 2013, constituindo, então, o universo desta pesquisa.

Destaca-se que, desse universo, sete IES apresentam IGC igual a $3(53,85 \%)$ e que, quanto à gestão financeira, dez IES são particulares, representando aproximadamente 76,92\%. Dessa forma, é possível afirmar que o universo de pesquisa, em maior parte, é constituído por BES de IES particulares com IGC igual a 3.

Após o delineamento do universo, iniciou-se a fase de levantamento e coleta dos documentos institucionais aplicados à catalogação das BES. Na primeira etapa, buscou-se levantar informações nos sites das IES referentes à criação e/ou adoção de documentos institucionais aplicados ao processo de catalogação, desenvolvidos pela BES, ou pela Rede de Cooperação de Bibliotecas.

De acordo com a pesquisa realizada não foram encontrados informações e/ou documentos dessa natureza, nos sites institucionais. Sendo assim, iniciou-se a segunda etapa de coleta de dados, a qual consistiu em contatar os 
bibliotecários responsáveis pela BES por e-mail e/ou por telefone para investigar a existência de algum documento institucional empregado para o auxílio do processo de catalogação na Instituição e, em caso afirmativo, solicitar uma cópia para análise.

Salienta-se que se optou por solicitar documentos institucionais aplicados à catalogação, sem restringir unicamente às políticas institucionais, por entender que, muitas vezes, as Uls apresentam documentos aplicados a esse processo, mas com emprego de termos distintos.

Os nomes das Instituições mantenedoras das BES objetos desta pesquisa não são aqui divulgados pois se compreende que os documentos fornecidos são de uso interno de cada Instituição e não estão disponíveis, em sua maioria, para acesso público.

Das treze BES contatadas, oito (61,54\%) afirmaram possuir documentação institucional formalizada com diretrizes aplicadas à catalogação. No entanto, desse total, duas delas não disponibilizaram documentos para análise, e uma UI, gentilmente, forneceu dois documentos institucionais.

Todavia, das cinco BES (38,46\%) que afirmaram não possuir documentação formalizada especificamente destinada ao processo de catalogação, duas enviaram, para análise, documentos institucionais com outras finalidades, que, segundo os gestores, também apresentam diretrizes aplicadas ao processo de catalogação.

Para a análise dos nove documentos coletados, elaborou-se um roteiro com doze itens (Tabela 1), com a finalidade de investigar a adequação, ou não, dos referidos documentos aos requisitos necessários para uma Política Institucional de Catalogação.

De acordo com os autores apresentados na Tabela 1, onze itens devem estar contidos em uma Política Institucional de Catalogação, e somente um item, apresentado no final da referida tabela, não deve compor tal documento.

Tabela 1. Roteiro para análise dos documentos coletados.

\begin{tabular}{|c|c|c|}
\hline & Elementos & Autores \\
\hline \multirow{9}{*}{ Deve conter } & Denominar-se política & $\begin{array}{l}\text { Carneiro (1985), Vergueiro (1989), Rubi } \\
\text { (2004) e Silva (2009) }\end{array}$ \\
\hline & Apresentar objetivos e finalidades do documento & $\begin{array}{l}\text { Carneiro (1985), Vergueiro (1989), Rubi } \\
\text { (2004) e Silva (2009) }\end{array}$ \\
\hline & Exibir período de atualização/revisão do documento & Bio (1985) e Read (2003) \\
\hline & $\begin{array}{l}\text { Definir os registros do conhecimento que são ou não } \\
\text { catalogados na Instituição (escopo) }\end{array}$ & Silva (2009) \\
\hline & $\begin{array}{l}\text { Documentar as prioridades da catalogação da } \\
\text { Instituição }\end{array}$ & Silva (2009) \\
\hline & Detalhar o nível de catalogação adotado na Instituição & Silva (2009) \\
\hline & $\begin{array}{l}\text { Determinar o controle de autoridades e de outros } \\
\text { pontos de acesso realizado na Instituição }\end{array}$ & Silva (2009) e Machado et al. (2013) \\
\hline & $\begin{array}{l}\text { Formalizar participação em redes de cooperação } \\
\text { bibliográfica }\end{array}$ & Oliveira e Cianconi (2013) \\
\hline & $\begin{array}{l}\text { Registrar as tecnologias aplicadas à catalogação da } \\
\text { Instituição }\end{array}$ & Silva (2009) \\
\hline
\end{tabular}


Tabela 1. Roteiro para análise dos documentos coletados (continuação).

\begin{tabular}{l|l|l}
\hline & \multicolumn{1}{|c}{ Elementos } & \multicolumn{1}{|c}{ Autores } \\
\hline & $\begin{array}{l}\text { Registrar as tecnologias aplicadas à catalogação da } \\
\text { Instituição }\end{array}$ & Silva (2009) \\
\cline { 2 - 3 } & $\begin{array}{l}\text { Apontar as regras e instrumentos auxiliares aplicáveis à } \\
\text { catalogação da Instituição }\end{array}$ & Silva (2009) e Santos e Corrêa (2009) \\
\cline { 2 - 4 } & $\begin{array}{l}\text { Apontar as responsabilidades dos catalogadores da } \\
\text { Instituição referentes à inserção dos registros nos } \\
\text { catálogos bibliográficos próprios e/ou coletivos }\end{array}$ & Silva (2009) \\
\hline \multirow{2}{*}{ Não deve conter } & $\begin{array}{l}\text { Não incluir orientações técnicas sobre como deve ser } \\
\text { realizada a descrição bibliográfica e a determinação } \\
\text { dos pontos de acesso na Instituição }\end{array}$ & Bio (1985) e Almeida (2005) \\
\hline
\end{tabular}

Fonte: Elaboração Própria

O roteiro para análise dos documentos fornecidos foi elaborado com base no estudo de pesquisadores que abordam o tema Política Institucional de Catalogação (SILVA, 2009; READ, 2009), mas também, de autores que estudam temáticas relacionadas a políticas institucionais (BIO, 1985); políticas aplicadas aos processos de Uls: tais como as políticas de indexação (CARNEIRO, 1985; RUBI, 2004) e as políticas de desenvolvimento de coleções (VERGUEIRO, 1989); planejamento em UI (ALMEIDA, 2005), e processo de catalogação (SANTOS; CORRÊA, 2009; MACHADO et al., 2013; OLIVEIRA; CIANCONI, 2013).

A opção por utilizar autores que não abordam diretamente a temática Política Institucional de Catalogação ocorreu pela escassez de estudos científicos relacionados ao referido tema, conforme apresentado por Souza (2015). Desse modo, os autores que fundamentaram esta pesquisa possuem contribuições, em suas áreas de pesquisa, que podem ser aplicadas às referidas políticas, uma vez que se entende que os princípios de planejamento e de estruturação de políticas institucionais podem ser adotados, com suas devidas adequações, por qualquer processo em uma UI, visto que esta deve ser pensada como uma organização (MACIEL; MENDONÇA, 2006).

A seguir serão apresentados os resultados obtidos, com base na análise realizada com o roteiro desenvolvido.

\section{Resultados}

O universo de estudo desta pesquisa foi constituído de nove documentos: destes sete foram disponibilizados por BES que afirmaram empregá-los no processo de catalogação, e dois documentos foram fornecidos por BES que informaram possuir documentação com orientações genéricas para as atividades desenvolvidas.

Após a análise dos documentos, verificou-se que dos nove documentos coletados, somente três apresentam diretrizes exclusivas para o processo de catalogação, e seis contém diretrizes para outras atividades de processamento técnico, tais como preparação e circulação de acervo, e desenvolvimento de coleções em conjunto com as diretrizes aplicadas à catalogação.

Desse modo, é possível afirmar que a maioria das BES $(66,67 \%)$ não possui uma documentação formalizada exclusiva para o processo de catalogação, visto que tais BES empregam documentos institucionais com orientações que englobam diversas atividades, dentre elas a de catalogação.

Quanto à natureza dos documentos fornecidos pelas BES, notou-se uma grande diversidade de tipologias, destacando-se os documentos no formato de Regimento Interno e de Artigo Científico como os mais heterogênicos, com terminologias diferentes entre si, comprovando a premissa de que as Uls empregam nomes 
distintos para documentos com finalidades semelhantes. A pesquisa constatou que nenhum documento possui a denominação Política Institucional de Catalogação, e cinco deles são denominados de manuais.

Esse fator sublinha a necessidade de as BES diferenciarem institucionalmente políticas institucionais de manuais de procedimentos, pois ambos são documentos elaborados para auxiliar seus colaboradores na busca pela eficiência das atividades desenvolvidas, mas com intenções distintas e complementares (ALMEIDA, 2005).

Quanto aos objetivos e às finalidades, constatou-se que sete documentos apresentam pelo menos um desses elementos no corpo do texto, indicando que a maior parte dos documentos fornecidos $(77,78 \%)$ possui objetivos e/ou finalidades especificadas.

A respeito da atualização dos documentos fornecidos, verificou-se que o mais antigo é de 2007, e o mais recente é de 2015. Mesmo que as políticas institucionais não apresentem um prazo médio de atualização requerido, enfatiza-se a necessidade de atualização constante dessas e o alinhamento das suas diretrizes às mudanças ocorridas nas atividades desenvolvidas pelas BES (BIO, 1985; READ, 2003).

Relativamente ao escopo e às prioridades de catalogação, dois documentos (22,22\%) especificam em seu corpo a restrição de suas diretrizes a determinados tipos de registros do conhecimento, e nenhum documento define prioridades para a catalogação na instituição. De acordo com a coleta de dados e a literatura abordada nesta pesquisa, destaca-se a relevância de diretrizes estabelecidas nas políticas para a otimização do processo de catalogação e para a minimização dos gastos e retrabalhos (SILVA, 2009).

No que diz respeito à determinação do nível de descrição bibliográfica usado na BES, verificou-se que três documentos (33,33\%) apresentam em seu corpo referida informação, demostrando baixa presença desse elemento nos documentos analisados.

Verificou-se a importância da determinação do nível de descrição bibliográfica na diretriz administrativa norteadora da catalogação, pois referido elemento visa a contribuir com a eficiência do processo e com a qualidade dos recursos bibliográficos gerados, assim como os elementos: escopo e prioridades de catalogação (SILVA, 2009).

Todos os documentos analisados apresentam algum tipo de diretriz relacionada ao controle de autoridade e de pontos de acesso na catalogação. Salienta-se que, mesmo não possuindo orientações institucionais específicas para o controle autoridade e de pontos de acesso, quatro documentos fornecidos contêm indicações de instrumentos auxiliares para tal atividade.

Quanto à natureza dos nove documentos analisados, seis deles são destinados a guiar as atividades desenvolvidas nas BES em nível de Rede de Bibliotecas Institucional. Com isso, é possível afirmar que a maioria das BES (62,5\%) que disponibilizaram seus documentos para análise integram Redes de Cooperação em nível Institucional, por meio das quais podem compartilhar recursos, conhecimentos, experiências, serviços e atividades, como a catalogação cooperativa (OLIVEIRA; CIANCONI, 2013).

Mediante análise dos documentos fornecidos, foi possível verificar que cinco BES utilizam o Sistema Automatizado Pergamum, e duas delas fazem uso do Sistema Automatizado Sophia. Desse modo, constatou-se que sete BES realizam catalogação automatizada e utilizam o AACR2 e o Formato de Intercâmbio Bibliográfico Machine Readable Cataloguing para o Século XXI (MARC 21), pois ambos são base para fundamentar sistemas automatizados para a catalogação, como o Pergamum e o Sophia.

Assim, pode-se concluir também que a maioria das BES (87,5\%) faz uso das Tecnologias de Informação e Comunicação (TICs), dentre elas os catálogos bibliográficos automatizados, para auxiliar nos serviços de processamento técnico e recuperação da informação.

No que se relaciona à indicação de regras e instrumentos auxiliares empregados na catalogação, todos os documentos apresentam diretrizes acerca da adoção das regras do AACR2 e a citação de instrumentos auxiliares internos ou externos às IES, como, por exemplo, catálogos bibliográficos e de autoridade, manuais de catalogação, manuais de sistemas automatizados e manuais do Formato Bibliográfico MARC 21. 
A respeito das responsabilidades, constatou-se que a maior parte dos documentos analisados $(77,78 \%)$ apresenta algum tipo de indicação de responsabilidade para os colaboradores das BES ou da Rede de Biblioteca Institucional, referente ao processo de catalogação desenvolvido na Instituição.

Conforme Silva (2009), é função das Políticas Institucionais de Catalogação registrar o posicionamento da UI quanto às responsabilidades dos catalogadores na autoria dos registros bibliográficos realizados em catálogos próprios (ou coletivos), bem como documentar a responsabilidade assumida pelo bibliotecário gestor do setor de processamento técnico de coordenar e de supervisionar a catalogação realizada pelos demais catalogadores.

Com base na análise do elemento responsabilidade, foi possível também identificar os diferentes contextos de catalogação em que se encontram as BES estudadas. Diante desse contexto, verificou-se a presença de uma BES participante de Rede de Bibliotecas que realiza a catalogação de forma centralizada e de uma BES que exerce a catalogação de modo descentralizado.

No que concerne ao elemento orientações técnicas, notou-se que a maioria dos documentos analisados $(88,89 \%)$ apresenta algum tipo de determinação relacionada às atividades do processo de catalogação, tais como exemplos de Campos MARC 21; orientações a respeito do preenchimento das tabelas de catalogação presentes nos Sistemas Automatizados Pergamum e Sophia; fluxogramas; e estabelecimento de acervos como padrões institucionais para a catalogação de determinados registros do conhecimento.

Diante disso, salienta-se a necessidade de diferenciação institucional dos diversos documentos administrativos que podem ser elaborados para auxiliar no processo de catalogação. De acordo com Almeida (2005), os fluxogramas e os manuais de serviço são exemplos de instrumentos administrativos que contêm procedimentos que visam ao estabelecimento de métodos de execução de atividades rotineiras e do detalhamento da maneira como devem ser executadas, bem como da sua sequência.

Uma Política Institucional de Catalogação não deve apresentar em seu corpo determinações de métodos e sequência de atividades técnicas referentes à catalogação e, consequentemente, fluxogramas e orientações técnicas, uma vez que estes se constituem como instrumentos administrativos com finalidades distintas das apresentadas por políticas institucionais (BIO, 1985; ALMEIDA, 2009).

Com a diferenciação dos documentos que podem ser empregados nas atividades de catalogação, como as diretrizes administrativas (políticas institucionais) e os instrumentos administrativos (manuais, fluxogramas, entre outros), as BES poderão garantir suas corretas utilizações, de modo que os objetivos que motivaram a elaboração de tais documentos sejam alcançados, colaborando, assim, com o cumprimento da missão dessas BES.

Dentro desse contexto, ressalta-se que a criação de um instrumento administrativo, como o Manual de Catalogação, não substitui a elaboração de uma diretriz administrativa, como a Política Institucional de Catalogação, pois cada documento apresenta finalidades próprias que se complementam, devendo ser utilizados em conjunto na UI, de modo a maximizar a qualidade do processo de catalogação.

Assim, é possível afirmar que nenhum dos nove documentos analisados apresentou os onze elementos que devem constar em uma Política Institucional de Catalogação de acordo com o roteiro desenvolvido. Os elementos mínimos presentes em todos os documentos foram: indicativo de data de elaboração; diretrizes para controle de autoridades; e indicação de regras e/ou instrumentos auxiliares adotados. O elemento prioridades de catalogação não estava contido em nenhum dos documentos fornecidos.

Com base nos elementos necessários definidos para a política institucional e de acordo com os autores da literatura da área da Biblioteconomia e da área da Administração empregados neste trabalho, é possível afirmar que nenhum dos nove documentos analisados são Políticas Institucionais de Catalogação, uma vez que não apresentam todos os requisitos levantados. 


\section{Considerações finais}

As Políticas Institucionais de Catalogação são constituídas de conjunto de diretrizes que visam a orientar os catalogadores de uma UI, ou de uma Rede de Cooperação de Uls, sobre a tomada de decisão em suas atividades cotidianas de catalogação, de modo a alinhar as atividades de descrição bibliográfica, determinação de pontos de acesso e dados de localização aos seus objetivos institucionais (BIO, 1985; SILVA, 2009).

Nesse sentido, este estudo alcançou seus objetivos, pois compreendeu a análise da criação e do uso de Políticas Institucionais de Catalogação em BES de IES credenciadas pelo MEC, com IGC igual ou superior a 3 , em 2013, situadas no município de Florianópolis, o que permitiu traçar um panorama de como ocorre a catalogação nessas Uls e quais documentos são utilizados para auxiliar seus catalogadores.

Por meio da análise dos nove documentos fornecidos, constatou-se que a maioria das BES utiliza as TICs para auxiliar no processo de catalogação, uma vez que $87,5 \%$ dessas documentaram o emprego de Catálogos Bibliográficos Automatizados e de Sistemas Automatizados para as atividades de tratamento técnico e de circulação do acervo.

Verificou-se ainda que $66,67 \%$ dos documentos analisados não são exclusivos para o processo de catalogação, apresentando diretrizes para diversas atividades desenvolvidas na UI.

Contudo, destaca-se que nenhum dos documentos analisados apresentou diretrizes referentes às prioridades de catalogação adotadas na BES, e os elementos requeridos para uma Política Institucional de Catalogação localizados nesta análise foram: indicativo de data de elaboração; diretrizes para controle de autoridades; e indicação de regras e/ou instrumentos auxiliares adotados.

Como resultado da análise dos nove documentos fornecidos, apurou-se que nenhum desses contém todos os elementos requeridos para uma Política Institucional de Catalogação. Sendo assim, nenhum dos documentos analisados pode ser considerado uma Política Institucional de Catalogação, pois não apresentou os requisitos mínimos necessários para ser caracterizado como tal.

As autoras compreendem que ao desenvolver e ao aplicar as referidas políticas em BES, as mesmas proporcionam benefícios como: diminuição de retrabalhos e de gastos desnecessários de recursos, e aumento no rendimento dos catalogadores e na qualidade dos produtos de catalogação.

Este estudo visou contribuir com a área de estudo da catalogação, uma vez que aprofundou a temática sobre as Políticas Institucionais de Catalogação. Como trabalhos futuros, sugere-se o desenvolvimento de pesquisas aplicadas a outros tipos de Uls, como, por exemplo, bibliotecas especializadas e bibliotecas públicas. Além disso, recomenda-se a realização de pesquisas referentes à utilização de Políticas Institucionais de Catalogação em outros Estados do Brasil e em nível internacional.

\section{Referências}

ALMEIDA, Maria Christina Barbosa de. Planejamento de bibliotecas e serviços de informação. 2. ed. rev. e ampl. Brasília, DF: Briquet de Lemos, 2005.

ALVES, Magda. Como escrever teses e dissertações: um roteiro passo a passo. 2. ed. Rio de Janeiro: Elsevier, 2007.

BIO, Sérgio Rodrigues. Sistemas de informação: um enfoque gerencial. São Paulo: Atlas, 1985.

BRANCO, Zuleika de Souza et al. Controle de qualidade em catalogação cooperativa. In: SEMINÁRIO NACIONAL DE BIBLIOTECAS UNIVERSITÁRIAS, 18, 2014. Anais... Belo Horizonte: UFMG, 2014. Disponível em: <https://www.bu.ufmg.br/snbu2014/wp-content/uploads/trabalhos/159-1763.pdf >. Acesso em: 25 fev. 2017.

BRASIL. Instituto Nacional de Estudos e Pesquisas Educacionais Anísio Teixeira. Índice Geral de Cursos (IGC). Brasília: INEP, 2015a. Disponível em: <http://portal.inep.gov.br/indice-geral-de-cursos-igc->. Acesso em: 25 fev. 2017.

BRASIL. Ministério da Educação. e-MEC. Instituições de Educação Superior e Cursos Cadastrados. [Brasília]: MEC, 2015b. Disponível em: <http://emec.mec.gov.br/>. Acesso em: 28 fev. 2017. 
CARNEIRO, Marília Vidigal. Diretrizes para uma política de indexação. R. Esc. Bibliotec. UFMG, Belo Horizonte, v. 14, n. 2, p. 221-241, set. 1985. Disponível em: <http://www.brapci.ufpr.br/brapci/v/a/2649>. Acesso em: 24 fev. 2017.

CUNHA, Murilo Bastos da; CAVALCANTI, Cordélia Robalinho de Oliveira. Dicionário de biblioteconomia e arquivologia. Brasília: Brinquet de Lemos: 2008.

FLICK, Uwe. Introdução à pesquisa qualitativa. Tradução Joice Elias Costa. 3. ed. Porto Alegre: Artmed, 2009

FUJITA, Mariângela Spotti Lopes; RUBI, Milena Polsinelli; BOCCATO, Vera Regina Casari. O contexto sociocognitivo do catalogador em bibliotecas universitárias [...]. DataGramaZero, v. 10, n. 2, 2009. Disponível em: <http://www.brapci.ufpr.br/brapci/v/a/5311>. Acesso em: 24 fev. 2017.

KOONTZ, Harold; O'DONNELL, Cyril; WEIHRICH, Heinz. Administração: organização, planejamento e controle. 14. ed. São Paulo: Pioneira, 1987. v. 2. (Biblioteca Pioneira de administração e negócios).

MACIEL, Alba Costa; MENDONÇA, Marília Alvarenga Rocha. Bibliotecas como organizações. Rio de Janeiro: Interciência; Niterói: Intertexto, 2006. 94p.

MACHADO, Denise Ramires et al. A cada autor, seu nome. A cada nome, seu documento [...]. In: ENCONTRO INTERNACIONAL DE CATALOGADORES, 9, 2013. Anais... Rio de Janeiro: Biblioteca Nacional, 2013. Disponível em: $<$ http://www.enacat.ufscar.br/index.php/ eic-enacat/eic-enacat/paper/viewFile/22/6>. Acesso em: 24 jul. 2016.

MARCONI, Marina de Andrade; LAKATOS, Eva Maria. Técnicas de pesquisa [...]. 7. ed. São Paulo: Atlas, 2013.

MEY, Eliane Serrão Alves; SILVEIRA, Naira Christofelli. Catalogação no plural. Brasília: Briquet de Lemos, 2009.

OLIVEIRA, Caroline Brito de; CIANCONI, Regina de Barros. Cooperação, compartilhamento e colaboração: caso da rede de bibliotecas e centros de informação em arte no Estado do Rio de Janeiro (REDARTE/RJ). BJIS, Marília (SP), v. 7, n. especial, p. 224-246, $1^{\circ}$ sem. 2013. Disponível em: <http://www2. marilia.unesp.br/revistas/index.php/bjis/article/view/3126>. Acesso em: 28 fev. 2017.

OLIVEIRA, Djalma de Pinho Rebouças de. Sistemas, organização e métodos: uma abordagem gerencial. 18. ed. São Paulo: Atlas, 2009.

POPPER, Rudolf. A elaboração de manuais na empresa. 2. ed. São Paulo: Pioneira, 1981.

READ, Jane M. Cataloguing without tears [...]. Oxford, UK: Chandos Publishing, 2003.

ROCHA, Eliana da Conceição; GOMES, Suely Henrique de A. Gestão da qualidade em unidades de informação. Ci. Inf., Brasília, v. 22, n. 2, p. 142-152, maio/ago. 1993. Disponível em: <http://revista.ibict.br/ciinf/article/download/501/501>. Acesso em: 25 fev. 2017.

RUBI, Milena Polsinelli. A política de indexação na perspectiva do conhecimento organizacional. 2004. 135 f. Dissertação (Mestrado em Ciência da Informação) - Faculdade de Filosofia e Ciências, Universidade Estadual Paulista, Marília/SP. Disponível em: <https://www.marilia.unesp.br/Home/Pos-Graduacao/Cienciadalnformacao/Dissertacoes/ rubi mp me mar.pdf>. Acesso em: 24 fev. 2017.

SANTOS, Plácida Leopoldina Ventura Amorim da Costa; CORRÊA, Rosa Maria Rodrigues. Catalogação: trajetória para um código internacional. Niterói: Intertexto, 2009.

SANTOS, Plácida Leopoldina Ventura Amorim da Costa; PEREIRA, Ana Maria. Catalogação: breve história e contemporaneidade. Niterói: Intertexto, 2014.

SILVA, Armando Jorge. Política de catalogação para as Bibliotecas da Rede Nacional de Bibliotecas Públicas. Lisboa: Direcção-Geral do Livro e das Bibliotecas, 2009. Disponível em: <http://rcbp.dglb.pt/pt/ServProf/Documentacao/Documents/PoliticaCatalogacaoDGLBfev2009.pdf>. Acesso em: 24 fev. 2017.

SOUSA, Brisa Pozzi de. Políticas para representação descritiva: ponderações para discussão. RBBD, São Paulo, v. 11, n. especial, p. 238-254, 2015. Disponível em: <https://rbbd.febab.org.br/rbbd/article/view/508/427>. Acesso em: 24 fev. 2017.

SPUDEIT, Daniela; FÜHR, Fabiane. Planejamento em unidades de informação: qualidade em operações de serviços na Biblioteca do SENAC Florianópolis. Bibl. Univ. Belo Horizonte, v. 1, n. 1, p. 41-49, jan./jun. 2011. Disponível em: $<$ https://www.bu.ufmg.br/rbu/index.php/localhost/article/viewFile/16/18>. Acesso em: 24 fev. 2017.

VERGUEIRO, Waldomiro. Desenvolvimento de coleções. São Paulo: Polis, 1989.

VOSGRAU, Sonia Regina Caselhas et al. Manual de catalogação do SBU/UNICAMP [...]. In: SEMINÁRIO NACIONAL DE BIBLIOTECAS UNIVERSITÁRIAS, 16, 2010. Anais... Rio de Janeiro: SIBI/UFRJ, 2010. Disponível em: $<$ http://docplayer.com.br/7874496-Manual-de-catalogacao-do-sbu-unicamp-uma-ferramenta-para-gestao-da-qualidade-dainformacao.html>. Acesso em: 24 fev. 2017. 


\section{Dados dos autores}

Priscilla Lüdtke Espíndola

Mestranda em Gestão de Unidades de Informação da Universidade do Estado de Santa Catarina.

priscillaludtke@gmail.com

Ana Maria Pereira

Professora do Programa de Pós-graduação em Gestão da Informação da Universidade do Estado de Santa Catarina (PPGInfo/UDESC).

anamariapere@gmail.com

Recebido - Received: 2017-04-25

Aceitado - Accepted: 2017-12-31

\section{$((c))$ EY}

This work is licensed under a Creative Commons Attribution 4.0

United States License.

\section{ULIS D-Serkf}

This journal is published by the University Library System of the University of Pittsburgh as part of its D-Scribe Digital Publishing Program and is cosponsored by the University of Pittsburgh Press. 